DOI: 10.12731/2658-6649-2020-12-3-94-107

УДК 316.346

\title{
ОБОСНОВАНИЕ ДЕЙСТВИЙ ПО МИНИМИЗАЦИИ ГЕРОНТОЛОГИЧЕСКОГО ЭЙДЖИЗМА СОГЛАСНО РЕКОМЕНДАЦИЯМ ВСЕМИРНОЙ ОРГАНИЗАЦИИ ЗДРАВООХРАНЕНИЯ
}

Климацкая Л.Г., Шпаков А.И., Зайцева О.И., Фуряева Т.В.

Цель: представить аналитический обзор научной литературы по проблеме геронтологического эйджизма и видение авторов по внедрению программы действий Всемирной организаиии здравоохранения (ВОЗ) для предупреждения данного явления в современном обществе.

Результаты. Программа ВОЗ направлена на иелевую аудиторию (пожилье люди) и состоит из 6 фундаментальных положений: распространенность эйджизма в мире; причины или детерминанты эйджизма; последствия эйджизма на индивидуальном уровне и на уровне общества; стратегии для минимизации проявлений эйджизма; система показателей для количественной оченки различных аспектов эйджизма и его проявлений; наиболее эффективные способы формирования понимания проблемь в обществе и объяснение понятий возраста и старения.

Заключение. Проводимые в рамках рекомендаций ВОЗ и «Стратегии действий в интересах граждан старшего поколения в Российской Федерации до 2025 года» мероприятия помогут переосмыслить восприятие феномена старения населения и позволят более эффективно использовать предоставленные возможности по предупреждению проявлений геронтологического эйджизма.

Ключевые слова: эйджизм; пожилье люди; рекомендачии Всемирной организации здравоохранения.

\section{VALIDITY SUPPORT FOR ACTIONS ON MINIMIZATION OF GERONTOLOGICAL AGEISM ACCORDING TO THE RECOMMENDATIONS OF THE WORLD HEALTH ORGANIZATION}

\section{Klimatckaia L.G., Shpakou A.I., Zaitseva O.I., Furiaeva T.V.}

Aim: to present an analytical review of the scientific literature on the problem of gerontological ageism and the authors' vision to implement the World 
Health Organization (WHO) action program to prevent this phenomenon in modern society.

Results. The WHO program is aimed at the target audience (elderly people) and consists of 6 fundamental provisions: the prevalence of ageism in the world, the causes or determinants of ageism, the consequences of ageism at the individual level and at the level of society, strategies to minimize ageism, a system of indicators for quantitative assessment of various aspects of ageism and its manifestations, the most effective ways of forming an understanding of the problem in society and explanation of the concepts of age and aging.

Conclusion. Carried out within the framework of WHO recommendations and the "Strategy of actions in the interests of elderly citizens in the Russian Federation until 2025", the activities will help to rethink the perception of the phenomenon of aging of the population and allow more effective use of the provided opportunities to prevent manifestations of gerontological ageism.

Keywords: ageism; elderly people; recommendations of the World Health Organization.

\section{Введение}

Проблема старения населения является одним из важнейших вызовов для социальной политики и общественного здравоохранения [1]. В современном демографическом сценарии поддержание адекватного уровня благосостояния и здоровья пожилых людей имеет принципиальное значение [2]. Старение является естественным процессом, но то, как общество воспринимает своих пожилых граждан и то, как сами пожилые люди рассматривают старость, предопределяет отношение к ним [3]. С другой стороны, увеличение продолжительности жизни и рост числа пожилых людей, скорее всего, приведет к увеличению спроса на медицинское и долгосрочное социальное обслуживание [4].

Цель: представить аналитический обзор научной литературы по проблеме геронтологического эйджизма и видение авторов по внедрению программы действий Всемирной организации здравоохранения (ВО3) для предупреждения данного явления в современном обществе.

\section{Результаты}

Пожилые люди как социальная группа требуют внимания не только со стороны государства (социальное обеспечение, медико-социальная реабилитация), но и со стороны ученых - для выявления очевидных и скрытых проблем жизнедеятельности в данный возрастной период $[5,6]$. 
Возрастные изменения являются неизбежными и зависят от ряда физических, социальных, экономических, политических и глобальных внешних факторов. Траектория старения непредсказуема, и неуверенность, возникающая из-за незнания особенностей, как человек будет стареть, может проявиться в форме эйджизма.

Создатель концепции эйджизма Роберт Батлер определил это явление в обществе как социальную стереотипизацию и дискриминацию людей по возрастному признаку [7]. Эйджизм может проявляться в различных формах, включая предвзятое отношение, дискриминационную практику или институциональные меры политики, способствующие закреплению стереотипных представлений. Пожилые люди, проживающие в учреждениях социального обслуживания, которым предоставляются медико-социальные услуги, могут подвергаться риску дискриминации как с точки зрения структуры услуг, так и в связи с поведением обслуживающего персонала [8].

Не существует единого мнения относительно концепции геронтологического эйджизма и его причин. Опираясь на теорию интерсекциональности, утверждается, что дискриминация не основывается исключительно на возрасте, а скорее на множестве иных характеристик, таких как пол, внешний вид, финансовое положение и социально-экономический статус [9]. Хотя в настоящее время признается, что эйджизм может быть направлен на любую возрастную группу, данное явление в отношении пожилых людей до сих пор в научной среде привлекает наибольшее внимание [10].

Всемирная организация здравоохранения (ВО3) подтверждает, что с быстрыми темпами старения населения возрастают масштабы деструктивного обращения с пожилыми людьми, что проявляется в виде формирования стереотипов, предрассудков, отчуждения и дискриминации отдельных людей или групп населения по возрастному признаку [11]. Эйджистские предрассудки - это тип эмоций, который часто связан с когнитивным процессом стереотипирования и может включать выражение уничижительного отношения, которое затем приводит к дискриминационному поведению. В свою очередь, геронтологическую дискриминацию можно определить как «неуместное и потенциально несправедливое обращение», основанное на принадлежности к группе пожилых людей [12].

В основу эффективности глобальной кампании по минимизации проявлений эйджизма ВО3 рекомендует положить проведение работы по преодолению индивидуальных и социальных негативных представлений, стереотипов и форм поведения, мотивированных возрастом человека, а 
также изменить деятельность институтов, которые либо косвенно укрепляют эйджизм, либо не способствуют его пресечению [13].

Программа действий ВОЗ по предупреждению эйджизма направлена на целевую аудиторию (пожилые люди) и включает в себя поиск ответов на 6 фундаментальных вопросов: 1. Распространенность эйджизма в мире; 2 . Причины или детерминанты эйджизма; 3. Последствия эйджизма на индивидуальном уровне и на уровне общества; 4. Стратегии для минимизации проявлений эйджизма; 5. Система показателей для количественной оценки различных аспектов эйджизма и его проявлений; 6. Наиболее эффективные способы формирования понимания проблемы в обществе и стимулирования переосмысления понятий возраста и старения [13].

Далее на основании анализа научных источников представляем наше видение внедрения программы действий ВОЗ по предупреждению эйджизма и оказанию медико-социальной помощи пожилым людям с возрастассоциируемыми заболеваниями.

1. Распространенность эйджизма в мире.

Эйджизм является довольно распространенным явлением. В отличие от других форм дискриминации в обществе, он социально приемлем и обычно не встречает серьезного противодействия из-за его неявного и подсознательного характера [14]. Начиная с детства, и по мере взросления, человек сталкивается с эйджизмом по отношению к себе и проявляет его по отношению к окружающим в результате подсознательного принятия господствующих в обществе предрассудков, негативных представлений и стереотипов о пожилых людях [15].

В мире насчитывается около 600 миллионов людей в возрасте 60 лет и старше. К 2025 г. это число может удвоиться, а к 2050 г. достигнет 2 миллиардов. Исследования показывают, что эйджизм может быть распространен даже шире, чем другие проявления дискриминации. Это имеет серьезные последствия как для самих пожилых людей, так и для всего общества [16].

2. Причины или детерминанты эйджизма.

В качестве определяющих детерминант эйджизма рассматриваются факторы, которые могут объяснить причины данного явления. В большинстве исследований, включенных в современные обзоры, рассматриваются стереотипы и дискриминация людей в зависимости от возраста и пола. Возрастная специфика проявляется в том, что молодежь склонна не признавать свое участие в эйджистских практиках. Это проявляется недостатком геронтологической компетентности (особенно у возрастных групп 18-29 и 30-39 лет) и специфическим корпоративизмом в виде де- 
структивной профессиональной солидарности в более старшем возрасте [17]. С увеличением возраста острота восприятия эйджизма повышается и достигает максимума после 60 лет.

С учетом гендерной детерминации эйджизма следует отметить выраженное отрицание обсуждать это явление у мужчин и избегание ответа у женщин. Что касается мужчин, их эйджистские проявления обусловлены снижением нормативности поведения и трудностями в коммуникации с пожилыми людьми. У женщин четко выражено психологическое неприятие старости и процесса старения из-за недостаточной геронтологической компетентности [8]. Другие детерминанты могут дополнять основные (по возрасту и полу) на индивидуальном, межличностном (групповом) и на институциональном уровнях [18]. Исследования, объединяющие детерминанты для этих уровней важны, поскольку предоставляют не только информацию о геронтологическом эйджизме, но и могут указывать на возможность изменений негативного восприятия процесса старения [2].

3. Последствия эйджизма на индивидуальном уровне и на уровне общества.

Эйджизм оказывает прежде всего вредное воздействие на индивидуальное и общественное здоровье пожилых людей [19]. Существует два пути противопоставления последствиям эйджизма. Первый из них основан на способах, с помощью которых пожилые люди пытаются отмежеваться от старости [20]. В моделях успешного или активного старения он связан с хорошим здоровьем и высокой степенью участия в жизни общества. В противоположность ему, второй путь связан с неудовлетворенностью пожилых людей жизнью общества (на основе негативных последствий эйджизма) и проявляется в высоком уровне одиночества. Исследования, проведенные Levy et al. [1] показывают различный уровень взаимосвязи продолжительности жизни пожилых людей при оптимистическом и пессимистическом восприятии старения. Эйджизм может приводить к ослаблению веры в собственные силы, снижать работоспособность и повышать риск усугубления течения возрастассоцированных заболеваний. Негативные установки, связанные с эйджизмом, довольно широко распространены среди персонала и пациентов в медицинских и социальных учреждениях, что предопределяет с одной стороны, уязвимость пожилых людей, а с другой, препятствует найму на оплачиваемую работу лиц, осуществляющих уход [21].

4. Стратегии для минимизации проявлений эйджизма.

Для минимизации проявлений эйджизма необходимо новое понимание процесса старения среди всех поколений людей. Такое понимание должно 
основываться на отказе от устаревшего восприятия пожилых людей в качестве обузы, признании разнообразного опыта пожилых людей и готовности к поиску способов оптимизации организации общества. Действия, которые могут помочь в минимизации проявлений эйджизма, включают: законодательные мероприятия, проведение коммуникационных кампаний по расширению знаний о процессе старения и улучшению понимания этой проблемы в средствах массовой информации, среди общественности и лиц, формирующих политику [22, 23].

Одной из ключевых задач «Стратегии действий в интересах граждан старшего поколения в Российской Федерации до 2025 года» [24] становится создание общества для всех возрастов, включая формирование условий для использования знаний, опыта, потенциала граждан старшего поколения, проявление заботы об этих людях и оказание им необходимой помощи. Итогом реализации Стратегии станет сформированная система мер, направленных на повышение благосостояния и социально-культурного развития людей старшего возраста, укрепление их здоровья, повышение продолжительности жизни и активного долголетия. Общий посыл Стратегии является оптимистичным: при правильной антиэйджистской политике и достаточности качественных медицинских и социальных услуг процесс старения населения может рассматриваться как оптимальный и будет способствовать активному долголетию.

5. Система показателей для количественной оценки различных аспектов эйджизма и его проявлений.

Важным направлением становления и совершенствования количественной оценки различных аспектов эйджизма выступает формирование системы показателей, позволяющей давать ему детальную и всестороннюю статистическую характеристику масштабов распространения и последствий [25].

Общепринятыми инструментами оценки уровня эйджизма и отношения к пожилым людям являются стандартизированные опросники. Одна из первых шкал количественного определения эйджизма была разработана Lasher et al. в 1993 году [26]. Она основана на предположении, что беспокойство по поводу процесса старения является индикатором отношения к пожилым людям, а также одним из элементов адаптации к процессам собственного старения. Данный инструментарий широко используется для оценки профессиональной готовности персонала по уходу за пожилыми людьми.

Популярной для оценки среди исследователей количественных показателей эйджизма является шкала М. Фрабони, предложенная в 1990 году [27]. 
Суммарная оценка проводится по ответам на вопросы трех классических шкал: «Возрастные стереотипы и предрассудки», «Дискриминация и негативное эмоциональное отношение» и «Отчуждение, избегание». Более высокий результат указывает на максимальную возрастную предвзятость, что позволяет оценить как когнитивный, так и аффективный компоненты эйджизма, в том числе: эмоциональность, стереотипы, отношения между поколениями и уровень субъективно переживаемого явления возрастной дискриминации. Шкала Когана [28] является одной из самых известных и широко используется в международных исследованиях. Рекомендуется ее применение для сравнительной оценки и определения эффективности геронтологических знаний и компетенций.

Представленные инструменты для количественной оценки отношения к пожилым людям, чаще всего содержат специфические суждения, на основании которых обследуемое лицо определяет позицию путем предоставления ответа по шкале Лайкерта.

6. Наиболее эффективные способы формирования понимания проблемы в обществе и стимулирования переосмысления понятий возраста и старения Маргарет Чен [29], используя последние данные исследований о сущности процесса старения, отмечает, что многие распространенные суждения, касающиеся понятия пожилого возраста основываются на устаревших стереотипах. Потеря работоспособности, обычно ассоциируемая со старением, не всегда связана с фактическим возрастом человека. Несмотря на то, что большинство пожилых людей имеют возрастассоцируемые заболевания, пожилой возраст не означает зависимость от других людей. Кроме того, старение гораздо меньше влияет на расходы системы здравоохранения, по сравнению, например, с высокой стоимостью новых медицинских технологий. Преимущества, которые могут быть упущены для функциональной поддержки пожилых людей, дороже обойдутся обществу. Рекомендуемый подход к феномену старения населения, требующий коренного изменения функционирования системы здравоохранения от моделей, основанных на лечении болезней, к предоставлению комплексной помощи, продолжает внедряться в Российской Федерации.

\section{Заключение}

Проводимые в рамках рекомендаций ВОЗ и «Стратегии действий в интересах граждан старшего поколения в Российской Федерации до 2025 года» мероприятия помогут переосмыслить восприятие феномена старения населения и позволят более эффективно использовать предоставлен- 
ные возможности по предупреждению проявлений геронтологического эйджизма.

Конфликт интересов. Авторы не заявляют о конфликте интересов.

Статья подготовлена при поддержке гранта РФФИ №20-51300002Bel_a (проект БРФФИ-РФФИ М20Р-006).

\section{Список литературы}

1. Levy B.R., Slade M., Chang E-S. et al. Ageism amplifies cost and prevalence of health conditions // Gerontologist. 2020, vol. 60, no. 1, pp. 174-181. DOI: 10.1093/geront/gny131.

2. Rychtař́ková J. Perception of population ageing and age discrimination across EU countries // Population and Economics. 2019, vol. 3, no. 4, pp. 1-29. DOI: 10.3897/popecon.3.e49760.

3. Климацкая Л.Г., Зайцева О.И. Межпоколенные отношения - современные молодые и старшее поколение // Сибирский вестник специального образования. 2014. № 4 (12). С. 20-24.

4. Carr D.C. \& Komp K.S. (eds.). Gerontology in the Era of the Third Age: Implications and Future Steps. Springer Publications, 2011. pp. 1-10.

5. Колпина Л.В. Эйджизм в обслуживании пожилых граждан учреждениями здравоохранения и социальной защиты: монография. Ульяновск: Зебра, 2015. 128 с.

6. Деревянных Е.В., Балашова Н.А., Яскевич Р.А., Москаленко О.Л. Анализ частоты встречаемости факторов риска сердечно-сосудистых заболеваний среди медицинских работников пожилого возраста. Siberian Journal of Life Sciences and Agriculture. 2019, Том 11, №2, C. 155-166. DOI: 10.12731/26586649-2019-11-2-155-166.

7. Butler R.N. Ageism: a foreword // J Soc Issues. 1980. vol. 36, no. 2, pp. 8-11. DOI: 10.1111/j.1540-4560.1980.tb02018.x.

8. Marques S., Mariano J., Mendonça J. et al. Determinants of Ageism against Older Adults: A Systematic Review // Int. J. Environ. Res. Public Health. 2020, 17, 2560. DOI:10.3390/ijerph17072560.

9. Krekula C., Nikander P., \& Wilińska M. Multiple marginalizations based on age: gendered ageism and beyond. In L. Ayalon \& C. Tesch-Römer (eds.). Contemporary perspectives on ageism. Berlin: Springer, 2018, vol. 19. pp. 33-50.

10. Marcus J., Fritzsche B. A. One size doesn't fit all: Toward a theory on the intersectional salience of ageism at work // Organizational Psychology Review. 2015, vol. 5, no. 2, pp. 168-188. 
11. World report on ageing and health. 2016. URL: https://apps.who.int/ iris/bitstream $/$ handle $/ 10665 / 186463 / 9789244565049$ rus. pdf? sequence $=10 \&$ isAllowed=y (accessed November 17, 2020).

12. Ageing and life-course. Geneva: World Health Organization. 2018. Available from: URL: http://www.who.int/ageing/ageism/en/ (accessed November 17, 2020).

13. Officera A., de la Fuente-Núñez V. A global campaign to combat ageism // Bull World Health Organ. 2018, vol. 96, pp. 299-300. DOI: 10.2471/BLT.17.202424.

14. UNECE Policy Brief on Ageing. March 2020. No. 23. URL: http://www.unece. org/fileadmin/DAM/pau/age/Policy_briefs/ECE_WG-1_34.pdf (accessed November 22, 2020).

15. Wilson D.M., Errasti-Ibarrondo B., Low G. Where are we now in relation to determining the prevalence of ageism in this era of escalating population ageing? // Ageing Res Rev. 2019, vol. 51, pp.78-84. DOI: 10.1016/j.arr.2019.03.001.

16. Levy B.R., Slade M.D., Murphy T.E. et al. Association between positive age stereotypes and recovery from disability in older persons // JAMA. 2012, vol.308, no 19, pp: 1972-1973. DOI: 10.1001/jama.2012.14541.

17. Колпина Л.В., Городова Т.В. Геронтологический эйджизм: причины возникновения и проблемы преодоления // Фундаментальные исследования. 2015, № 2-17, С. 3871-3874.

18. Шпаков А.И., Климацкая Л.Г., Зайцева О.И. и др. Некоторые аспекты геронтологического эйджизма в учреждениях здравоохранения // Современные проблемы науки и образования. 2017, № 5. URL: http://www. science-education.ru/ru/article/view?id=26997 (дата обращения: 26.11.2020).

19. Chang E.S., Kannoth S., Levy S. et al. Global reach of ageism on older persons' health: A systematic review // PLoS One. 2020, vol. 15, no. 1, e0220857. DOI: 10.1371/journal.pone.0220857.

20. Voss P., Bodner E., Rothermund K. Ageism: The Relationship between Age Stereotypes and Age Discrimination. In: Ayalon L., Tesch-Römer C. (eds) Contemporary Perspectives on Ageism International Perspectives on Aging. 2018, vol 19. Springer, Cham. DOI:10.1007/978-3-319-73820-8_2.

21. Becca R Levy B.R., Slade M.D., Kunkel S.R. et al. Longevity increased by positive self-perceptions of aging // J Pers Soc Psychol. 2002, vol. 83, no 2, pp. 261-270. DOI: 10.1037/0022-3514.83.2.261.

22. Georgantzi N. The European union's approach towards ageism. In L. Ayalon \& C. Tesch-Römer (eds.) // Contemporary perspectives on ageism: vol. 19. International perspectives on aging. Berlin: Springer. pp. 341-368.

23. Козлов Е.В., Деревянных Е.В., Балашова Н.А., Яскевич Р.А., Москаленко О.Л. Влияние социально-экономических факторов на качество жизни 
больных хронической обструктивной болезнью легких в условиях коморбидности // Siberian Journal of Life Sciences and Agriculture. 2019, Том 11, No 3, C. 103-120.

24. Распоряжение Правительства РФ от 05.02.2016 N 164-р «Об утверждении Стратегии действий в интересах граждан старшего поколения в Российской Федерации до 2025 года». URL: https://mintrud.gov.ru/ministry/ programms/37/2 (accessed November 22, 2020).

25. Ayalon L., Dolberg P., Mikulionienè S. et al. A systematic review of existing ageism scales // Ageing Res Rev. 2019, vol. 54, e:100919. DOI: 10.1016/j. arr.2019.100919. Epub 2019 Jun 19.

26. Lasher K.P., Faulkender P. J. Measurement of aging anxiety: evelopment of the Anxiety about Aging Scale // Int J AgingHum Dev. 1993, Vol. 37, No 4, pp. 247-259.

27. Fraboni M., Saltstone R., Cooper D. et al. The Fraboni Scale of Ageism // Canadian Journal on Aging. 1990, vol. 9, no 1, P. 56-66.

28. Doherty M., Mitchell E.A., O ' Neill S. Attitudes of Healthcare Workers towards Older People in a Rural Population: A Survey Using the Kogan Scale // Nurs Res Pract. 2011; vol. 2011, Article ID 352627, 7 p. DOI: 10.1155/2011/352627.

29. Выступление Генерального директора д-ра Маргарет Чен на Семидесятой сессии Всемирной ассамблеи здравоохранения. 2017, URL: http://158.232.12.119/ $\mathrm{dg} /$ speeches/2017/address-seventieth-assembly/ru/ (accessed November 22, 2020).

\section{References}

1. Levy B.R., Slade M., Chang E-S. et al. Ageism amplifies cost and prevalence of health conditions. Gerontologist. 2020, vol. 60, no. 1, pp. 174-181. DOI: 10.1093/geront/gny131.

2. Rychtaříková J. Perception of population ageing and age discrimination across EU countries. Population and Economics. 2019, vol. 3, no. 4, pp. 1-29. DOI: 10.3897/popecon.3.e49760.

3. Klimackaia L.G., Zajceva O.I. Mezhpokolennye otnoshenija - sovremennye molodye i starshee pokolenie [Intergenerational relations - modern young and the older generation]. Sibirskij vestnik special'nogo obrazovanija, 2014. no 4 (12), pp. 20-24.

4. Carr D.C. \& Komp K.S. (eds.). Gerontology in the Era of the Third Age: Implications and Future Steps. Springer Publications, 2011. pp. 1-10.

5. Kolpina L.V. Jejdzhizm v obsluzhivanii pozhilyh grazhdan uchrezhdenijami zdravoohranenija i social'noj zashhity: monografija [Ageism in servicing elderly citizens by health and social protection institutions: monograph]. Ul'janovsk: Zebra, 2015. $128 \mathrm{p}$. 
6. Derevyannich E.V., Balashova N.A., Yaskevich R.A., Moskalenko O.L. Analiz chastoty vstrechaemosti faktorov riska serdechno-sosudistyh zabolevanij sredi medicinskih rabotnikov pozhilogo vozrasta [Analysis of the frequency of occurrence of risk factors of cardiovascular diseases among health care workers in elderly]. Siberian Journal of Life Sciences and Agriculture, 2019, no 11 (2), pp. 155-166. DOI: 10.12731/2658-6649-2019-11-2-155-166.

7. Butler R.N. Ageism: a foreword. J Soc Issues. 1980. vol. 36, no. 2, pp. 8-11. DOI: 10.1111/j.1540-4560.1980.tb02018.x.

8. Marques S., Mariano J., Mendonça J. et al. Determinants of Ageism against Older Adults: A Systematic Review. Int. J. Environ. Res. Public Health. 2020, 17, 2560. DOI:10.3390/ijerph17072560.

9. Krekula C., Nikander P., \& Wilińska M. Multiple marginalizations based on age: gendered ageism and beyond. In L. Ayalon \& C. Tesch-Römer (eds.). Contemporary perspectives on ageism. Berlin: Springer, 2018, vol. 19. pp. 33-50.

10. Marcus J., Fritzsche B. A. One size doesn't fit all: Toward a theory on the intersectional salience of ageism at work. Organizational Psychology Review. 2015, vol. 5 , no. 2, pp. 168-188.

11. World report on ageing and health. 2016. URL: https://apps.who.int/ iris/bitstream/ handle/10665/186463/9789244565049_rus. pdf? sequence $=10 \&$ isAllowed $=\mathrm{y}$ (accessed November 17, 2020).

12. Ageing and life-course. Geneva: World Health Organization. 2018. URL: http:// www.who.int/ageing/ageism/en/ (accessed November 17, 2020).

13. Officera A., de la Fuente-Núñez V. A global campaign to combat ageism. Bull World Health Organ. 2018, vol. 96, pp. 299-300. DOI: 10.2471/BLT.17.202424.

14. UNECE Policy Brief on Ageing. March 2020. No. 23. URL: http://www.unece. org/fileadmin/DAM/pau/age/Policy_briefs/ECE_WG-1_34.pdf (accessed November 22, 2020).

15. Wilson D.M., Errasti-Ibarrondo B., Low G. Where are we now in relation to determining the prevalence of ageism in this era of escalating population ageing? Ageing Res Rev. 2019, vol. 51, pp.78-84. DOI: 10.1016/j.arr.2019.03.001.

16. Levy B.R., Slade M.D., Murphy T.E. et al. Association between positive age stereotypes and recovery from disability in older persons. JAMA. 2012, vol.308, no 19, pp: 1972-1973. DOI: 10.1001/jama.2012.14541.

17. Kolpina L.V., Gorodova T.V. Gerontologicheskij jejdzhizm: prichiny vozniknovenija i problemy preodolenija [Gerontological ageism: causes and overcoming problems]. Fundamental'nye issledovanija, 2015, no 2-17, pp. 3871-3874.

18. Shpakou A.I., Klimackaia L.G., Zajceva O.I., Naumov I.A., Laskene S.L. Nekotorye aspekty gerontologicheskogo jejdzhizma $\mathrm{v}$ uchrezhdenijah 
zdravoohranenija [Some aspects of gerontological ageism in healthcare institutions], Modern problems of science and education, 2017, no 5. URL: http:// www.science-education.ru/ru/article/view?id=26997 (accessed 26.11.2020).

19. Chang E.S., Kannoth S., Levy S. et al. Global reach of ageism on older persons' health: A systematic review. PLoS One. 2020, vol. 15, no. 1, e0220857. DOI: 10.1371/journal.pone.0220857.

20. Voss P., Bodner E., Rothermund K. Ageism: The Relationship between Age Stereotypes and Age Discrimination. In: Ayalon L., Tesch-Römer C. (eds) Contemporary Perspectives on Ageism International Perspectives on Aging. 2018, vol 19. Springer, Cham. DOI:10.1007/978-3-319-73820-8_2.

21. Becca R Levy B.R., Slade M.D., Kunkel S.R. et al. Longevity increased by positive self-perceptions of aging. J Pers Soc Psychol. 2002, vol. 83, no 2, pp. 261-270. DOI: 10.1037/0022-3514.83.2.261.

22. Georgantzi N. The European union's approach towards ageism. In L. Ayalon \& C. Tesch-Römer (eds.). Contemporary perspectives on ageism: vol. 19. International perspectives on aging. Berlin: Springer. pp. 341-368.

23. Kozlov E.V., Derevyanykh E.V., Balashova N.A., Yaskevich R.A., Moskalenko O.L. Vlijanie social'no-jekonomicheskih faktorov na kachestvo zhizni bol'nyh hronicheskoj obstruktivnoj bolezn'ju legkih v uslovijah komorbidnosti [The effect of socio-economic factors on the quality of life in patients with chronic obstructive lung disease in conditions of comorbidity]. Siberian Journal of Life Sciences and Agriculture, 2019, no 11 (3), pp. 103-120.

24. Rasporjazhenie Pravitel'stva RF ot 05.02.2016 N 164-r «Ob utverzhdenii Strategii dejstvij v interesah grazhdan starshego pokolenija v Rossijskoj Federacii do 2025 goda» [Order of the Government of the Russian Federation from 05.02.2016 N 164-r "On Approval of the Strategy for Action in the Interests of Senior Citizens in the Russian Federation until 2025"]. 2016. https://mintrud. gov.ru/ministry/programms/37/2 (accessed November 22, 2020).

25. Ayalon L., Dolberg P., Mikulionienė S. et al. A systematic review of existing ageism scales. Ageing Res Rev. 2019, vol. 54, e:100919. DOI: 10.1016/j. arr.2019.100919. Epub 2019 Jun 19.

26. Lasher K.P., Faulkender P. J. Measurement of aging anxiety: evelopment of the Anxiety about Aging Scale. Int J AgingHum Dev. 1993, vol. 37, no 4, pp. 247-259.

27. Fraboni M., Saltstone R., Cooper D. et al. The Fraboni Scale of Ageism. Canadian Journal on Aging. 1990, vol. 9, no 1, P. 56-66.

28. Doherty M., Mitchell E.A., O ‘ Neill S. Attitudes of Healthcare Workers towards Older People in a Rural Population: A Survey Using the Kogan Scale. Nurs Res Pract. 2011; vol. 2011, Article ID 352627, 7 p. DOI: 10.1155/2011/352627. 
29. Vystuplenie General'nogo direktora d-ra Margaret Chen na Semidesjatoj sessii Vsemirnoj assamblei zdravoohranenija [Address by Dr Margaret Chan, Director-General, to the Seventieth World Health Assembly]. 2017, URL: http://158.232.12.119/dg/speeches/2017/address-seventieth-assembly/ru/ (accessed November 22, 2020).

\section{ДАННЫЕ ОБ АВТОРАХ}

Климацкая Людмила Георгиевна, профессор кафедры социальной педагогики и социальной работы, доктор медицинских наук Красноярский государственньй педагогический университет им. В.П. Астафьева

ул. Ады Лебедевой, 89, г. Красноярск, 660049, Российская Федерачия klimatskaya47@mail.ru

Шпаков Андрей Иванович, доцент кафедры теории физической культуры и спортивной медицины, кандидат медицинских наук Гродненский государственный университет им. Янки Купаль ул. Ожешко, 22, г. Гродно, 230023, Республика Беларусь shpakofff@tut.by

Зайцева Ольга Исаевна, главный научный сотрудник, доктор медицинских наук Федеральное государственное бюджетное научное учреждение «Научно-исследовательский институт медицинских проблем Севера» ул. Партизана Железняка, 32, Красноярск, 660022, Российская Федерачия 1081959@mail.ru

Фуряева Татьяна Васильевна, зав. кафедрой социальной педагогики и социальной работы, профессор, доктор педагогических наук Красноярский государственный педагогический университет им. В.П. Астафьева ул. Ады Лебедевой, 89, г. Красноярск, 660049, Российская Федераиия tat.fur130@mail.ru

\section{DATA ABOUT THE AUTHORS}

Klimatckaia Liudmila Georgievna, Professor of the Department of Social Pedagogy and Social Work, Doctor of Medicine 
Krasnoyarsk State Pedagogical University named after V. P. Astafiev

89, Ada Lebedeva Str., Krasnoyarsk, 660049, Russian Federation

klimatskaya47@mail.ru

ORCID:0000-0001-8926-2901

Shpakou Andrei Ivanovich, Associate Professor of the Department of Theory of Physical Culture and Sports Medicine, Cand. Sc. (Medicine) Yanka Kupala State University of Grodno

22, Ozheshko Str., Grodno, 230023, Republic of Belarus shpakofff@tut.by

ORCID: 0000-0003-4340-5211

Zaitseva Olga Isaevna, Chief Scientific Officer, Doctor of Medicine Scientific Research Institute of Medical Problems of the North 3g, Partisan Zheleznyak Str, Krasnoyarsk, 660022, Russian Federation 1081959@mail.ru ORCID: 0000-0001-7199-2308

Furiaeva Tatiana Vasilevna, Head of the Department of Social Pedagogy and Social Work, Professor, Doctor of Pedagogical Sciences 89, Ada Lebedeva Str., Krasnoyarsk, 660049, Russian Federation tat.fur130@mail.ru

ORCID: 0000-0002-7709-1102 